\title{
Post-traumatic stress disorder, resilience and vulnerability
}

\author{
Ayesha S. Ahmed
}

Abstract Post-traumatic stress disorder (PTSD), recognised as a diagnostic entity in 1980, was originally associated with combat or war experiences. It has since been recognised that it is prevalent in any population exposed to traumatic events. Although much has been written about the management of PTSD, the concepts of resilience and vulnerability have not received the same attention. This article reviews the conceptualisation, epidemiology and comorbidities of PTSD and highlights the factors underlying vulnerability and conveying resilience.

In the current geopolitical climate, political and social instabilities as well as natural and man-made calamities have been on the increase. Civil wars often result in atrocities, violence, forced migration and mass fatalities. Exposure to such events can lead to psychological strain and pathology. This pathology includes acute stress reaction, adjustment disorder and post-traumatic stress disorder (PTSD). Of these, PTSD is associated with the highest morbidity and is often underdiagnosed. This prompted my review of the literature on the different aspects of PTSD, with special emphasis on vulnerability and resilience.

\section{Conceptualisation}

The ICD-10 (World Health Organization, 1992) considers an event or situation of exceptionally threatening or catastrophic nature, which would be likely to cause pervasive distress in anyone, as the main aetiological agent for PTSD. For an ICD-10 diagnosis, the symptoms need to have lasted for at least a month and to have occurred within 6 months of the traumatic event.

Post-traumatic stress disorder was introduced as a diagnostic entity in the DSM classification in DSM-III (American Psychiatric Association, 1980). In the first and second versions of the DSM (American Psychiatric Association, 1952, 1968), stress response syndromes were described as transient reactive processes. If the psychological disturbances were chronic, another diagnosis had to be used. DSM-IV has gone further and incorporates the individual's reaction or emotional response to the traumatic event within the diagnostic criteria, requiring that 'the person's response involved intense fear, helplessness, or horror' (American Psychiatric Association, 1994: p. 428).

\section{Epidemiology}

The National Comorbidity Survey conducted in the USA between September 1990 and February 1992 using DSM-III-R (Kessler et al, 1995) revealed a lifetime prevalence of PTSD of $7.8 \%$ in the general population, with women (10.4\%) twice as likely as men (5\%) to develop the disorder at some point in their lives. The trauma most likely to be associated with PTSD was rape, with a $65 \%$ prevalence of raperelated PTSD in men and $45.9 \%$ in women. However, women were 17 times more likely to present with PTSD after rape. Other traumatic events associated with PTSD in women were physical abuse $(48.5 \%)$, threat with a weapon $(32.6 \%)$, molestation $(26.5 \%)$ and physical attack (21.3\%). For men, other common traumatic events were combat exposure (38.8\%), childhood neglect $(23.9 \%)$, physical abuse (22.3\%) and molestation (12.2\%). There is also evidence of gender specificity, with combat exposure being commonly associated with PTSD in men. In community samples of populations affected by war and forced migration, the prevalence of PTSD ranges between 14 and 37\% (Karunakara et al, 2004).

Ayesha Ahmed is a trainee psychiatrist at Bradgate Mental Health Unit (Glenfield General Hospital, Groby Road, Leicester LE3 9EJ, UK. Email: ayeshasahmed25@yahoo.co.uk). Her interest in post-traumatic stress disorder stems from involvement with the British Pakistani Psychiatrists Association's Earthquake Trauma Relief Initiative (ETRI) for the victims of the earthquake in Pakistan in October 2005. She has a keen interest in teaching and has set up a website, Simply Psychiatry (http://www.simplypsychiatry.co.uk) for the MRCPsych part I OSCE exam. 
A meta-analysis of the behavioural consequences of terrorism (DiMaggio \& Galea, 2006) indicates that in the year following a terrorist act the prevalence of PTSD in people directly affected by the act varies between 12 and $16 \%$. It also shows that this prevalence can be expected to decline by $25 \%$ over the course of that year.

Avoidance symptoms, especially numbing, are associated more strongly with chronic PTSD. Symptoms of hyperarousal are also significantly associated with chronicity but less strongly (Marshall et al, 2006). In the National Comorbidity Survey, the median time to remission was 36 months with treatment and 64 months without treatment, but in some people symptoms lasted up to 10 years (Kessler et al, 1995).

\section{Resilience and vulnerability}

Given that the majority of people exposed to traumatic events do not experience PTSD, what is it that protects them? In considering this question, Bonanno (2004) has defined resilience as the ability to maintain a state of normal equilibrium in the face of extremely unfavourable circumstances. To enhance resilience, it is necessary to have an understanding of its determinants. Various factors such as beliefs, attitudes, coping strategies, behaviours and psychosocial cohesion have been suggested as conveying protection or endorsing resilience in the face of trauma. Resilient individuals may show insight, initiative, humour, creativity and independence. It is a dynamic quality. There may be discontinuities in resilience as people, situations, opportunities and environment change.

Resilience and vulnerability are related concepts in a number of scientific disciplines but unlike resilience, vulnerability has not been conceptualised in a comprehensive manner. There are different disciplinary approaches to the concept of vulnerability. Vulnerability has been defined as the potential for loss (Mitchell, 1989) or the potential for casualty when exposed to a hazard or threat. The International Strategy for Disaster Reduction (2004) defines vulnerability as the predisposition of individuals or societies to be affected and the inability to manage disaster. Chambers (1989) divides vulnerability into external and internal factors. The external factors relate to external shocks and environmental stresses, whereas the internal factors are associated with inability to cope with trauma. Vulnerability is difficult to quantify but it may be increased or decreased depending on the type of action taken in dealing with it.

Multiple studies have consistently highlighted the following factors underlying vulnerability and resilience.

\section{Genetics}

It has been suggested that trauma victims who develop PTSD are more likely than those who do not to have parents and first-degree relatives with mood, anxiety and substance use disorders (Davidson et al, 1985). The children of Holocaust survivors who experienced PTSD were themselves more likely to develop the disorder than the children of survivors without PTSD (Yehuda et al, 1998). A study of prevalence of PTSD in monozygotic $v$. dyzygotic twins of Vietnam veterans has shown that genetic factors account for as much as $34 \%$ of PTSD symptoms (True et al, 1993).

\section{Neurobiology}

There is growing evidence that specific neurobiological dysfunctions are present in people with PTSD. In stressful or threatening situations, the sympathetic nervous system becomes activated and adrenaline and noradrenaline are released. Unrestrained activation of the sympathetic nervous system, leading to hypervigilance, anxiety and intrusive memories, has been seen in people with PTSD (Southwick et al, 1999), whereas resilient individuals may be able to restrict sympathetic activation to only dangerous or stressful situations (Morgan et al, 2000).

Neuropeptide $\mathrm{Y}$ is an amino acid released with noradrenaline on activation of the sympathetic system. One of its actions is to control the continued release of noradrenaline. Low levels of neuropeptide $Y$ have been seen in combat veterans with chronic PTSD (Rasmusson et al, 2000), and some studies have linked resilience with high levels of neuropeptide $\mathrm{Y}$.

Corticotrophin-releasing hormone $(\mathrm{CRH})$ and cortisol are important mediators of stress. In stressful situations, CRH is released from the hypothalamus into the hypothalamic-pituitary circulation, resulting in activation of the hypothalamic-pituitary axis and subsequent secretion of cortisol from the adrenal glands. This stress-induced increase in cortisol is constrained through a negative feedback system involving glucocorticoid and mineralocorticoid receptors. The ability to restrain CRH has been suggested to be associated with resilience (Charney, 2004), and increased levels of CRH in the cerebrospinal fluid (CSF) have been linked to PTSD (Bremner et al, 1997). Blunted hypothalamicpituitary axis response to stress has been implicated in susceptibility to PTSD, as patients exhibit low circulating cortisol levels (Cohen et al, 2006). There is evidence that this is due to enhanced negative feedback in the hypothalamic-pituitary axis secondary to enhanced glucocorticoid receptor 
sensitivity. Hyper-suppression of cortisol has also been noted with a dexamethasone suppression test, which suggests that cortisol receptors are more sensitive in people with PTSD (Yehuda et al, 1995). As elevated cortisol levels inhibit memory retrieval in healthy people, a pilot study was carried out in which low-dose (10 mg/day) cortisol was administered to reduce excessive retrieval of traumatic memories in people with chronic PTSD. The results indicated that low-dose cortisol reduces the cardinal symptoms of the disorder (Aerni et al, 2004).

Increased platelet 5-hydroxytryptamine (serotonin) concentration has been recorded in war veterans with psychotic PTSD and may be used as a trait marker of psychotic symptoms in the disorder but not as a state marker for the disorder itself (Pivac et al, 2006). Several clinical trials have reported increased urinary and plasma dopamine concentrations in PTSD (Hamner \& Diamond, 1993). The $\mathrm{D}_{2}$ dopamine receptor $(D R D 2)$ gene is associated with severe comorbid psychopathology (anxiety, insomnia, social dysfunction, somatic concerns and depression) in people with PTSD (Lawford et $a l, 2006)$.

\section{Brain structure}

People with post-traumatic disorder show morphological and functional abnormalities of the brain. Areas implicated include the amygdala, hippocampus and prefrontal cortex.

When conditioned stimuli are presented without the unconditioned stimuli, the conditioned fear response decreases. This forms the basis of extinction. The ventromedial prefrontal cortex plays a role in extinction as its lesions impair recall of extinction and its stimulation strengthens extinction memory. Compromise of extinction circuits in the ventromedial prefrontal cortex has been suggested in PTSD. Neural pathways, especially those linked to fear conditioning and consolidation of memory and extinction, play a role in vulnerability and resilience. It has been suggested that resilient individuals are less likely to consolidate emotional memories and have a greater ability to extinguish traumatic memories (Charney, 2004). Along with a hyporesponsive prefrontal cortex, hyperresponsive amygdala in PTSD has been suggested (McNally, 2006). The amygdala plays a central role in the processing and storage of memory of emotional events.

The hippocampus is another key region implicated in the pathogenesis of PTSD, with reduced hippocampal activity associated with more severe symptoms of the disorder (Astur et al, 2006). A study involving monozygotic twins in which one twin in each pair was a Vietnam war veteran (Pitman et $a l, 2006)$ revealed smaller hippocampal volume in both twins in pairs in which the veteran had PTSD compared with pairs in which the veteran did not. These results support the authors' hypothesis that hippocampal abnormalities represent antecedent and familial vulnerability for developing PTSD on exposure to a traumatic event.

In a study comparing twins in which one sibling in each pair had PTSD with a control group of twins in which neither had the disorder, Gurvits et al (2006) found that both twins in the PTSD pairs showed significantly higher scores on tests of soft neurological signs than did twins in the control group. This suggests that soft neurological signs may represent a familial vulnerability for developing PTSD.

\section{Psychosocial factors}

Many psychosocial factors underpin vulnerability. They include the nature of the trauma; the perception that one's life is at risk; strong initial emotional reaction (fright/fear and helplessness); witnessing someone being killed or seriously injured; and the demographic grouping of the survivor, including low socio-economic status, being divorced, widowed and unemployed. Being elderly, adolescent or a child and having lower education also increase susceptibility. Experiences of sexual assault, especially at an early age, and pre-existing mental health problems are related to greater susceptibility to lifetime PTSD, with prevalence being higher in women (Stuber et al, 2006). Unresolved childhood trauma increases the risk of PTSD more than seven-fold and has been associated with the avoidant rather than dissociative symptoms of the disorder (StovallMcClough \& Cloitre, 2006). A study of terrorism in Israel revealed that authoritarian beliefs and ethnocentrism were related to PTSD, suggesting that PTSD may be related to a defensive style of coping (Hobfoll et al, 2006). Lack of internal locus of control is a contributor to the development of PTSD. External factors such political, social, economic and environmental instability, and lack of resources may also increase susceptibility.

Above-average cognitive ability has been identified as a protective factor (McNally, 2006). Securely attached individuals exhibit fewer symptoms of PTSD (Fraley et al, 2006), whereas an avoidant style of attachment predicts increase in PTSD symptoms (Scarpa et al, 2006).

\section{Refugee experience}

Refugees present a particularly vulnerable group. They often come from regions where conflict of varying intensity has been present for long periods, leading to social and economic ruin. In civil wars there is seldom any distinction between soldiers and 
Table 1 Lifetime experience of psychiatric disorders for people with PTSD

$\begin{array}{lc}\text { Disorder (DSM-III-R) } & \begin{array}{c}\text { Lifetime experi- } \\ \text { ence of disorder, \% }\end{array} \\ \text { Major depressive disorder } & 48 \\ \text { Generalised anxiety } & 16 \\ \text { Panic } & 9.5 \\ \text { Social phobia } & 28 \\ \text { Alcohol abuse/dependence } & 40 \\ \text { Drug abuse/dependence } & 31 \\ \text { Conduct } & 29 \\ \text { Mania } & 9 \\ \text { Source: Kessler } \text { et al (1995). } & \end{array}$

civilians, forced recruitment is common and the final aim is extinction and destruction of a population rather than conquest of land.

The severity of trauma faced by refugees ranges from personal torture, the concept of which differs in different cultures, and incarceration to losses in combat. Refugees experience sequential stresses: the process of migration, loss of social role, stress of acculturation, change from a majority to minority status, social isolation and lack of knowledge about the norms of the new culture compound over time. It has been suggested that multiple traumatic events can increase the severity of PTSD symptoms (Karunakara et al, 2004). The assumption is that previous traumatic events increase vulnerability either through a direct dose effect or through the process of desensitisation.

\section{Comorbidity}

Post-traumatic stress disorder often coexists with other psychiatric disorders such as depression, anxiety disorders, somatisation and substance misuse. There is also evidence that people who develop PTSD have experienced other psychiatric disorders in the past (Table 1). Kessler et al (1995) found that $88.3 \%$ of men with PTSD and $79 \%$ of women with the disorder had a lifetime diagnosis of other psychiatric illness.

Depression and anxiety symptoms have been shown to be significantly higher among women and those reporting death threats as part of their traumatic experiences (Keller et al, 2006).

'Self-medication' with drugs and alcohol to reduce arousal symptoms has been suggested. An Australian national survey (Mills et al, 2006) revealed that alcohol was the most common substance of misuse by people with PTSD who had a comorbid substance use disorder. Analysing the data another way, of the national population with a substance use disorder, PTSD was most prevalent among those using opioids. It has also been reported that people who had experienced sexual abuse in childhood or adulthood had more symptoms of PTSD. They were also more likely to use drugs or alcohol to cope, to act sexually and to withdraw from people (Filipas \& Ullman, 2006).

In addition to psychiatric comorbidity, it has been suggested that chronic or elevated pain is associated with PTSD. Geracioti et al (2006) set out to test the hypothesis that concentrations of pain-transmitting neuropeptide substance $\mathrm{P}$ are elevated in people with PTSD. They found that marked increase in CSF substance $P$ concentrations occurred when patients were exposed to stimuli that provoked PTSD symptoms but not to neutral stimuli. In another study (Dahl et al, 2006), a significant association was found between severe chronic pain and PTSD. Use of analgesic medication is also higher in patients with PTSD (Schwartz et al, 2006).

\section{Misdiagnosis}

It is important to note that PTSD can go undiagnosed or can be misdiagnosed as refractory depression. Substance misuse and eating disorders often mask underlying PTSD, and flashbacks may be erroneously labelled as psychotic symptoms.

\section{Assessment}

Post-traumatic stress disorder is associated with considerable morbidity. Therefore in the aftermath of a traumatic event, it is crucial to identify people with psychological vulnerability in the at-risk population (Box 1). It is also important to discern whether the events are ongoing.

\section{Box 1 Vulnerability factors}

\section{Internal characteristics}

- Being female

- Low sense of safety

- Low sense of social support

- High trait neuroticism

- Pre-existing psychopathology

- Negative appraisal of the traumatic event

External factors

- Lower level of educational

- Immigrant status

- Previous traumatic events

- Severity of exposure (severe or prolonged trauma) 


\section{Box 2 Factors promoting resilience}

Internal characteristics

- Self-esteem

- Trust

- Resourcefulness

- Self-efficacy

- Internal locus of control

- Secure attachments

- Sense of humour

- Self-sufficiency

- Sense of mastery

- Optimism

- Interpersonal abilities such as social skills, problem-solving skills and impulse control

External factors

- Safety

- Religious affiliation

- Strong role models

- Emotional sustenance: the extent to which others provide the individual with understanding, companionship, sense of belonging and positive regard

Resilience can be evaluated by exploring internal and external resources such as those listed in Box 2 . To assess for vulnerability it is important to listen to the individual's subjective appraisal of the event and to ask about their use of coping strategies. Also explore prior exposure to traumatic events such as childhood adversities, current or past psychopathology, familial susceptibility and support networks.

Resilience can be measured using the ConnorDavidson Resilience Scale (Connor, 2006). This is self-rated and consists of 25 items, each rated on a 5-point scale. The total score ranges from 0 to 100, with higher score reflecting greater resilience. Other scales include the Resilience Scale for Adults (Friborg et al, 2003) and the Adolescent Resilient Scale (Oshio et al, 2003). The Stress Vulnerability Scale (Connor, 2006) measures the degree of perceived distress following setbacks. It is a self-rated, single-item, 11-point, visual analogue scale, with higher scores predicting greater vulnerability.

There are currently no validated, culturally and linguistically sensitive screening instruments for atrisk refugee populations.

No assumptions should be made about the meaning or the impact of traumatic events, as one's own reactions may be inconsistent with the patient's feelings and experiences. Refugees often find it difficult to engage with mental health services, and practitioners need to improve their understanding of the traditions, systems of meaning and priorities of such patients. Mental health service providers also need to be aware of their own cultural countertransference.

\section{Therapeutic interventions}

After a traumatic event, most people will be distressed but will prove to be resilient. For vulnerable individuals, identifying needs and making support available can promote resilience. Return to normality should be encouraged, along with provision of emotional and social support as soon as possible. Social support can lead to improvement in social skills and capacity for social adaptation. Involvement in creative activity may also enhance resilience.

Brief cognitive therapy (four or five sessions) initiated within 5 weeks of the event reduced the severity of PTSD symptoms in victims of assault (Foa et al, 1995). Cognitive-behavioural therapy can be used to identify resilient behaviour, coping strategies, automatic thoughts and underlying assumptions. Group work with trauma victims can provide an environment in which individuals can realise their own potential for self- healing, which can lead to enhanced autonomy and self-regard.

Early work on the use of drugs such as betaadrenergic blockers to block the action of stress hormones in the consolidation of traumatic memories has shown promising results (Pitman et al, 2002), but further study is necessary.

\section{Conclusions}

Trauma can have varied impact on individuals and communities. Knowledge of resilience and vulnerability factors can be of substantial benefit in the assessment and management of trauma victims. If risk factors are identified, screening and timely interventions can be employed to optimise outcome. At present there are no widely available interventions to promote resilience, although cognitive-behavioural therapy and group work can be effective.

\section{Declaration of interest}

None.

\section{References}

Aerni, A., Traber, R., Hock, C., et al (2004) Low-dose cortisol for symptoms of posttraumatic stress disorder. American Journal of Psychiatry, 161, 1488-1490.

American Psychiatric Association (1952) Diagnostic and Statistical Manual of Mental Disorders. APA. 
American Psychiatric Association (1968) Diagnostic and Statistical Manual of Mental Disorders (2nd edn) (DSM-II). APA.

American Psychiatric Association (1980) Diagnostic and Statistical Manual of Mental Disorders (3rd edn) (DSM-III). APA.

American Psychiatric Association (1994) Diagnostic and Statistical Manual of Mental Disorders (4th edn) (DSM-IV). APA.

Astur, R. S., St Germain, S. A., Tolin, D., et al (2006) Hippocampus function predicts severity of post-traumatic stress disorder. CyberPsychology and Behavior, 9, 234-240.

Bonanno, G. A. (2004) Loss, trauma, and human resilience: have we underestimated the human capacity to thrive after extremely aversive events? American Journal of Psychology, 59, 20-28.

Bremner, J. D., Licinio, J., Darnell, A., et al (1997) Elevated CSF corticotropin-releasing factor concentrations in posttraumatic stress disorder. American Journal of Psychiatry, 154, 624-629.

Chambers, R. (1989) Vulnerability. How the poor cope. IDS Bulletin, 20, 1-7.

Charney, D. S. (2004) Psychobiological mechanisms of resilience and vulnerability: implications for successful adaptation to extreme stress. American Journal of Psychiatry, 161, 195-216.

Cohen, H., Zohar, J., Gidron, Y., et al (2006) Blunted HPA axis response to stress influences susceptibility to posttraumatic stress response in rats. Biological Psychiatry, 59, 1208-1218.

Connor, K. M. (2006) Assessment of resilience in the aftermath of trauma. Journal of Clinical Psychiatry, 67 (suppl. 2), 46-49.

Dahl, S., Dahl, C. I., Sandvik, L., et al (2006) [Chronic pain in traumatized refugees]. Tidsskrift Nor Lægeforen, 126, 608-610.

Davidson, J., Swartz, M., Storck, M., et al (1985) A diagnostic and family study of posttraumatic stress disorder. American Journal of Psychiatry, 142, 90-93.

DiMaggio, C. \& Galea, S. (2006) The behavioral consequences of terrorism: a meta-analysis. Academic Emergency Medicine, 13, 559-566.

Filipas, H. H. \& Ullman, S. E. (2006) Child sexual abuse, coping responses, self-blame, posttraumatic stress disorder, and adult sexual revictimization. Journal of Interpersonal Violence, 21, 652-672.

Foa, E. B., Hearst-Ikeda, D. \& Perry, K. J. (1995) Evaluation of a brief cognitive-behavioral program for the prevention of chronic PTSD in recent assault victims. Journal of Consulting and Clinical Psychology, 63, 948-955.

Fraley, R. C., Fazzari, D. A., Bonanno, G. A., et al (2006) Attachment and psychological adaptation in high exposure survivors of the September 11th attack on the World Trade Center. Personality and Social Psychology Bulletin, 32, 538-551.

Friborg, O., Hjemdal, O., Rosenvinge, J. H., et al (2003) A new rating scale for adult resilience: what are the central protective resources behind healthy adjustment? International Journal of Methods in Psychiatric Research, 12, 65-76.

Geracioti, T. D., Jr., Carpenter, L. L., Owens, M. J., et al (2006) Elevated cerebrospinal fluid substance $\mathrm{p}$ concentrations in posttraumatic stress disorder and major depression. American Journal of Psychiatry, 163, 637-643.

Gurvits, T. V., Metzger, L. J., Lasko, N. B., et al (2006) Subtle neurologic compromise as a vulnerability factor for combatrelated posttraumatic stress disorder: results of a twin study Archives of General Psychiatry, 63, 571-576.

Hamner, M. B. \& Diamond, B. I. (1993) Elevated plasma dopamine in posttraumatic stress disorder: a preliminary report. Biological Psychiatry, 33, 304-306.

Hobfoll, S. E., Canetti-Nisim, D. \& Johnson, R. J. (2006) Exposure to terrorism, stress-related mental health symptoms, and defensive coping among Jews and Arabs in Israel. Journal of Consulting and Clinical Psychology, 74, 207-218.

International Strategy for Disaster Reduction (2004) Living with Risk. A Global Review of Disaster Reduction Initiatives. ISDR.

Karunakara, U. K., Neuner, F., Schauer, M., et al (2004) Traumatic events and symptoms of post-traumatic stress disorder amongst Sudanese nationals, refugees and Ugandans in the West Nile. African Health Sciences, 4, 83-93.

Keller, A., Lhewa, D., Rosenfeld, B., et al (2006) Traumatic experiences and psychological distress in an urban refugee population seeking treatment services. Journal of Nervous and Mental Disease, 194, 188-194.
Kessler, R. C., Sonnega, A., Bromet, E., et al (1995) Posttraumatic stress disorder in the National Comorbidity Survey. Archives of General Psychiatry, 52, 1048-1060.

Lawford, B. R., Young, R., Noble, E. P., et al (2006) The D2 dopamine receptor (DRD2) gene is associated with co-morbid depression, anxiety and social dysfunction in untreated veterans with post-traumatic stress disorder. European Psychiatry, 21, 180185.

Marshall, R. D., Turner, J. B., Lewis-Fernandez, R., et al (2006) Symptom patterns associated with chronic PTSD in male veterans: new findings from the National Vietnam Veterans Readjustment Study. Journal of Nervous and Mental Disease, 194, 275-278.

McNally, R. J. (2006) Cognitive abnormalities in post-traumatic stress disorder. Trends in Cognitive Sciences, 10, 271-277.

Mills, K. L., Teesson, M., Ross, J., et al (2006) Trauma, PTSD, and substance use disorders: findings from the Australian National Survey of Mental Health and Well-Being. American Journal of Psychiatry, 163, 652-658

Mitchell, J. K. (1989) Hazards research. In Geography in America (eds G. L. Gaile \& C. J. Willmott), pp. 410-424. Charles E. Merill.

Morgan, C. A., 3rd, Wang, S., Southwick, S. M., et al (2000) Plasma neuropeptide- $Y$ concentrations in humans exposed to military survival training. Biological Psychiatry, 47, 902-909.

Oshio, A., Kaneko, H., Nagamine, S., et al (2003) Construct validity of the Adolescent Resilience Scale. Psychological Reports, 93, 1217-1222.

Pitman, R. K., Sanders, K. M., Zusman, R. M., et al (2002) Pilot study of secondary prevention of posttraumatic stress disorder with propranolol. Biological Psychiatry, 51, 189-192.

Pitman, R. K., Gilbertson, M. W., Gurvits, T. V., et al (2006) Clarifying the origin of biological abnormalities in PTSD through the study of identical twins discordant for combat exposure. Annals of the New York Academy of Sciences, 1071, 242-254.

Pivac, N., Kozaric-Kovacic, D., Mustapic, M., et al (2006) Platelet serotonin in combat related posttraumatic stress disorder with psychotic symptoms. Journal of Affective Disorders, 93, 223-227.

Rasmusson, A. M., Hauger, R. L., Morgan, C. A., et al (2000) Biological Psychiatry, 47, 526-539.

Scarpa, A., Haden, S. C. \& Hurley, J. (2006) Community violence victimization and symptoms of posttraumatic stress disorder: the moderating effects of coping and social support. Journal of Interpersonal Violence, 21, 446-469.

Schwartz, A. C., Bradley, R., Penza, K. M., et al (2006) Pain medication use among patients with posttraumatic stress disorder. Psychosomatics, 47, 136-142.

Southwick, S. M., Bremner, J. D., Rasmusson, A., et al (1999) Role of norepinephrine in the pathophysiology and treatment of posttraumatic stress disorder. Biological Psychiatry, 46, 11921204

Stovall-McClough, K. C. \& Cloitre, M. (2006) Unresolved attachment, PTSD, and dissociation in women with childhood abuse histories. Journal of Consulting and Clinical Psychology, 74, 219-228.

Stuber, J., Resnick, H. \& Galea, S. (2006) Gender disparities in posttraumatic stress disorder after mass trauma. Gender Medicine, 3, 54-67.

True, W. R., Rice, J., Eisen, S. A., et al (1993) A twin study of genetic and environmental contributions to liability for posttraumatic stress symptoms. Archives of General Psychiatry, 50, 257-264.

World Health Organization (1992) The International Statistical Classification of Diseases and Related Health Problems, Tenth Revision (ICD-10). WHO.

Yehuda, R., Boisoneau, D., Lowy, M. T., et al (1995) Dose-response changes in plasma cortisol and lymphocyte glucocorticoid receptors following dexamethasone administration in combat veterans with and without posttraumatic stress disorder. Archives of General Psychiatry, 52, 583-593.

Yehuda, R., Schmeidler, J., Giller, E. L., et al (1998) Relationship between posttraumatic stress disorder characteristics of Holocaust survivors and their adult offspring. American Journal of Psychiatry, 155, 841-183. 


\section{MCQs}

1 As regards PTSD:

a it is overdiagnosed

$\mathrm{b}$ resilience is not a dynamic quality

c prevalence of PTSD is the same all over the world

d prior trauma does not increase susceptibility to PTSD

e chronic pain is associated with PTSD.

2 In PTSD:

a avoidance is associated with chronicity

$\mathrm{b}$ refugees are at no more risk than the indigenous population

c misdiagnosis as refractory depression is not a problem

d cortisol levels are high

e securely attached individuals exhibit more symptoms.

3 In the aetiology of PTSD:

a the hippocampus has no role

b locus of control has no role

c the sympathetic nervous system is not involved

d lower level of education is protective

e unresolved childhood trauma increases the risk.

4 Vulnerability factors include:

a male gender

b middle age

c internal locus of control

d good impulse control

e personality disorders.

5 Defence mechanisms used to deal with trauma include:

a identification

b denial

c rationalisation

d sublimation

e splitting.

\section{MCQ answers}

$\begin{array}{lllllll}1 & & 2 & & 3 & 4 & 5 \\ \text { a F } & \text { a T } & \text { a F } & \text { a F } & \text { a F } \\ \text { b F } & \text { b F } & \text { b F } & \text { b F } & \text { b T } \\ \text { c F } & \text { c F } & \text { c F } & \text { c F } & \text { c F } \\ \text { d F } & \text { d F } & \text { d F } & \text { d F } & \text { d F } \\ \text { e T } & \text { e F } & \text { e T } & \text { e T } & \text { e F }\end{array}$

